\title{
LETTERS
}

\section{Pachymeningitis in mixed connective tissue disease}

\section{K Ahmadi-Simab, P Lamprecht, M Reuter, W L Gross}

Ann Rheum Dis 2005;64:1656-1657. doi: 10.1136/ard.2004.035204

$\mathrm{P}$ achymeningitis is a rare illness which can be shown by magnetic resonance imaging (MRI) to be a thickening of the intracranial dura mater, when associated with an infectious, malignant, or rheumatic systematic disease. ${ }^{1-6}$ "Idiopathic hypertrophic cranial pachymeningitis" is also noticeable, and is based on a process of chronic inflammation whose cause is unclear. ${ }^{4}$ Typical symptoms are chronic headaches, facial pain, cerebella ataxia, cranial nerve failure, neuro-ophthalmic complications, including papilloedema.

We report on a 64 year old woman who presented with monthly progressive cephalgia, subfebrile temperatures, loss of weight, Raynaud's phenomenon, proximal myasthenia, arthritis, photosensitivity, and prickling paraesthesia. From this we diagnosed a mixed connective tissue disease, fulfilling at least three American College of Rheumatology (ACR) criteria, with a secondary vasculitis (pachymeningitis and polyneuropathy) and pulmonary disease (neutrophilic alveolitis).

A cerebral MRI scan showed initially and after 3 months clear thickening and enrichment of contrast dye in all meningeal structures (pachymeningitis), as well as widened ventricles I-III, with periventricular capping in the form of a

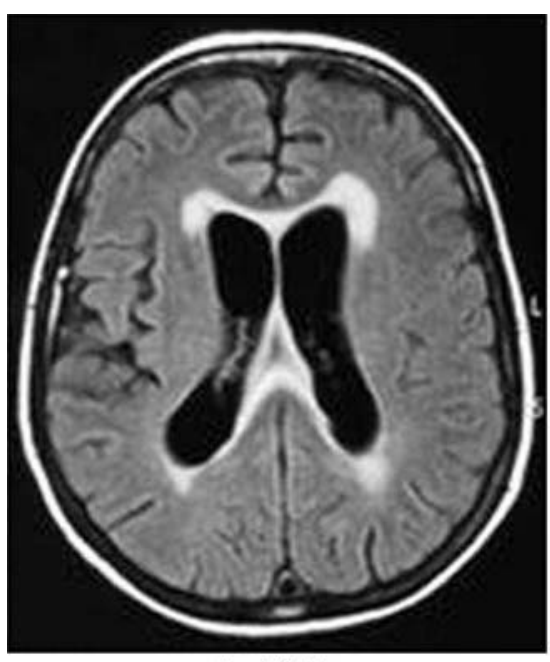

Dark fluid

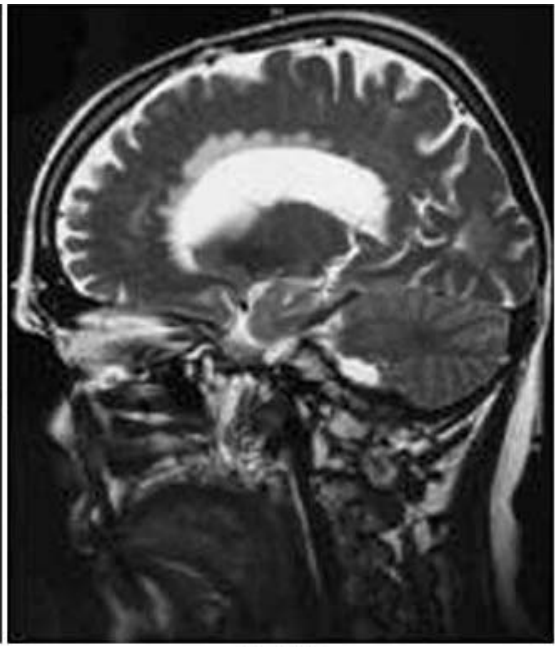

$\mathrm{T}_{2}$ TSE

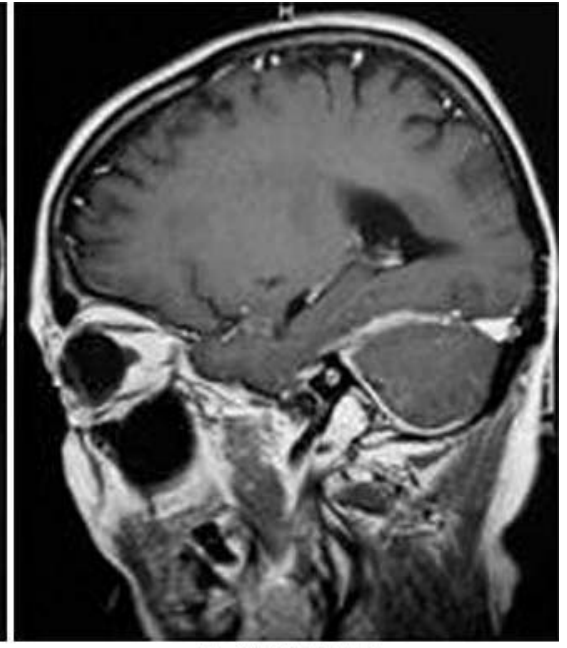

$T_{1}$ SE Gd-DTPA

Figure 1 Pachymeningitis and hydrocephalus in mixed connective tissue disease.

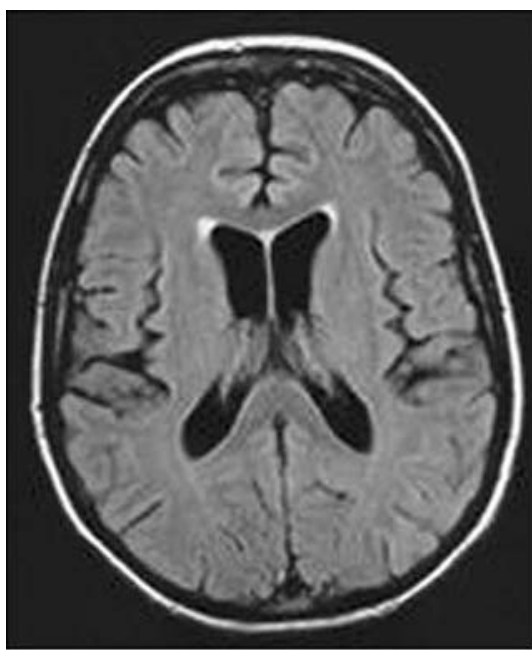

Dark fluid

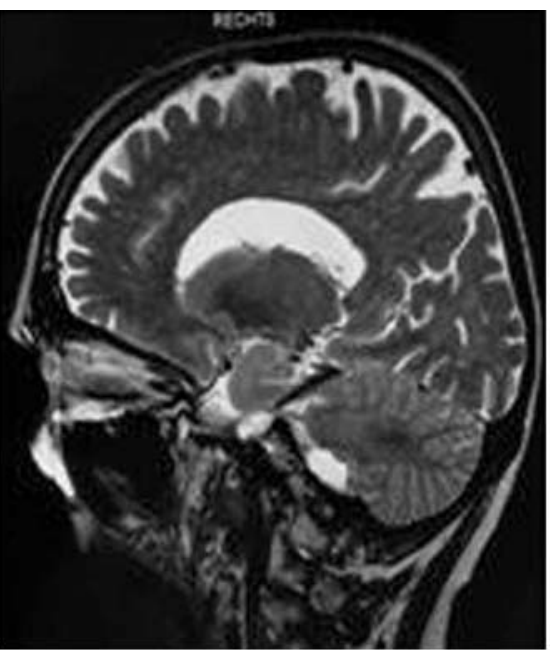

$\mathrm{T}_{2}$ TSE

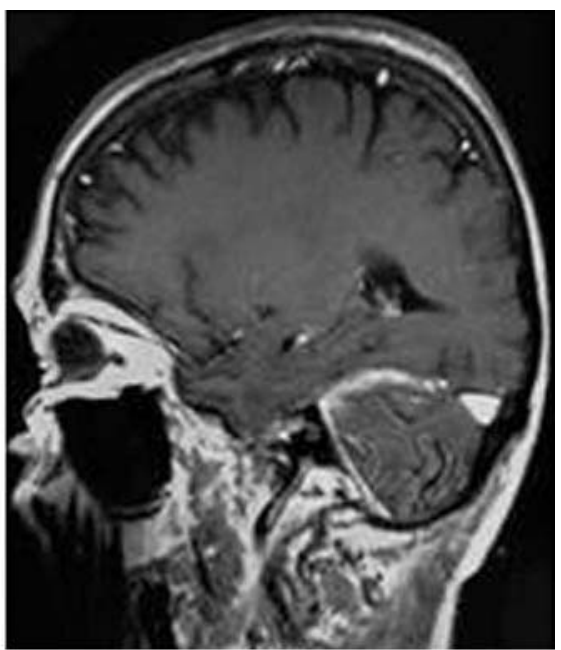

$T_{1}$ SE Gd-DTPA

Figure 2 Improvement of the pachymeningitis and hydrocephalus after treatment. 
hydrocephalus (fig 1). Because of the hydrocephalus, it was neurologically advisable not to perform a cerebrospinal fluid puncture. There was no indication of tuberculosis (chest $x$ ray examination, tuberculin test, sputum culture) or any other infection. The neoplasia investigation was also negative. An anamnestic investigation showed that there was no need to use ibuprofen or sulindac.

When the situation became life threatening we initiated immunosuppressive treatment with cyclophosphamide ( $100 \mathrm{mg} /$ day), as well as intravenous steroids (100 mg) initially. The initial intravenous cortisone treatment relieved the headache symptoms. Follow up examinations for up to 1 year (every 3 months) showed remission of clinical and MRI findings with this treatment (fig 2). Stable partial remission occurred after 8 months, and oral administration of cyclophosphamide was stopped. Treatment to preserve remission was changed to azathioprine (100 mg). The prednisone dose was finally reduced to $5 \mathrm{mg}$.

\section{Authors' affiliations}

K Ahmadi-Simab, P Lamprecht, W L Gross, Department of Rheumatology, University Hospital of Schleswig-Holstein, Campus Luebeck, and Rheumaklinik Bad Bramstedt, Ratzeburger Allee 160, 23538 Luebeck, Germany
M Reuter, Department of Radiology, University Hospital of SchleswigHolstein, Campus Kiel, Hegewischstr. 2, 24105 Kiel, Germany

Correspondence to: Dr K Ahmadi-Simab, ahmadi@rheuma-zentrum. de; ahmadi@ik-h.de

Accepted 28 March 2005

\section{REFERENCES}

1 Agildere AM, Tutar NU, Yucel E, Coskun M, Benli S, Aydin P. Pachymeningitis and optic neuritis in rheumatoid arthritis: MRI findings. Br J Radiol 1999;72:404-7.

2 Jinnah HA, Dixon A, Brat DJ, Hellmann DB. Chronic meningitis with cranial neuropathies in Wegener's granulomatosis. Case report and review of the literature. Arthritis Rheum 1997;40:573-7.

3 Joelson E, Ruthrauff B, Ali F, Lindeman N, Sharp FR. Multifocal dural enhancement associated with temporal arteritis. Arch Neurol 2000;57:119-22

4 Kupersmith MJ, Martin V, Heller G, Shah A, Mitnick HJ. Idiopathic hypertrophic pachymeningitis. Neurology 2004;62:686-94.

5 Li JY, Lai PH, Lam HC, Lu LY, Cheng HH, Lee JK, ef al. Hypertrophic cranial pachymeningitis and lymphocytic hypophysitis in Sjogren's syndrome. Neurology 1999;52:420-3.

6 Reinhold-Keller E, de Groot K, Holl-Ulrich K, Arlt AC, Heller M, Feller AC, et al. Severe CNS manifestations as the clinical hallmark in generalized Wegener's granulomatosis consistently negative for antineutrophil cytoplasmic antibodies (ANCA). A report of 3 cases and a review of the literature. Clin Exp Rheumatol 2001;19:541-9.

\section{Empyema in a patient treated with infliximab: it is not what it seems}

\section{A Bossink, S Thijsen, A J van Houte}

A 68 year old woman, treated with prednisone and infliximab for rheumatoid arthritis, presented with two periods of thoracic empyema in two subsequent winters. $H$ influenzae was cultured in the first infectious period and $S$ pneumoniae during the second. Direct stains, polymerase chain reaction, and cultures for mycobacteria remained negative in both periods. She was treated with intravenous antibiotics and a closed drainage system. Infliximab was discontinued after the first infectious period. Recovery was complete. Last winter no infections occurred.

Six month after the last infectious period a chest computed tomographic scan was made and immunoglobulins and mannose binding lectin (MBL, a key mediator of innate host immunity) were determined. Radiology showed no abnormalities. IgG2 was significantly decreased. IgG1, IgG3, and IgG4, IgA, and IgM levels were normal. Functional serum MBL was markedly low, correlating with the genotype heterozygote $\mathrm{XA} / \mathrm{YD} \mathrm{MBL}$ codon 1 variant in combination with a heterozygous promoter genotype, resulting in deficient production of functional MBL. One year after the second infection, after tapering prednisone to $10 \mathrm{mg}$ daily, she was vaccinated with a 23-valent pneumococcal polysaccharide vaccine and $H$ influenzae B polysaccharide conjugated with tetanus toxoid. The immune response against pneumococcal polysaccharide types 3, 4, and 9 was absent and against $H$ influenzae type B polysaccharide the response was normal.

Reduced IgG levels can be the result of long term prednisone treatment or chronic infection. ${ }^{1}$ Isolated IgG2 subclass deficiency may result in enhanced susceptibility to encapsulated bacteria. ${ }^{2}$ Another report suggests an increased susceptibility to invasive pneumococcal disease in homozygotes for MBL codon variants. ${ }^{3}$ It is tempting to speculate that the immunomodulating effect of infliximab contributed to the two episodes of thoracic empyema. However, to date, no reports have mentioned this kind of infection as a result of anti-tumour necrosis factor treatment.

We suggest that the combination of an IgG2 subclass deficiency with a heterozygote MBL codon variant and the use of steroids made this host more vulnerable to infection with encapsulated bacteria. In our opinion, in patients with infections with encapsulated bacteria after treatment with immunomodulating drugs, an assessment of the immune state should be considered.

\section{Authors' affiliations}

A Bossink, Heart Lung Centre, and Diakonessenhuis, Utrecht, The Netherlands

S Thiijsen, Diakonessenhuis, Utrecht, The Netherlands

A J van Houte, Diakonessenhuis, Utrecht and Antonius Ziekenhuis, Nieuwegein, The Netherlands

Correspondence to: Dr A Bossink, Bosboomstraat 1, Utrecht, The Netherlands; aikbossink@mac.com

Accepted 15 March 2005

\section{REFERENCES}

1 Oehling AG, Akdis CA, Schapowal A, Blaser K, Schmitz M, Simon HU. Suppression of the immune system by oral glucocorticoid therapy in bronchial asthma. Allergy 1997;52:144-54. 
2 Ekdahl K, Braconier JH, Svanborg C. Immunoglobulin deficiencies and impaired immune response to polysaccharide antigens in adult patients with recurrent community-acquired pneumonia. Scand J Infect Dis 1997;29:401-7.
3 Roy S, Knox K, Segal S, Griffiths D, Moore CE, Welsh KI, et al. MBL genotype and risk of invasive pneumococcal disease: a case control study. Lancet 2002;359:1569-73.

\title{
Superficial collections of fluid tophaceous material as clinical presentation of anorexia nervosa
}

\author{
C Garcia-Porrua, C Canedo, R Argueso, M A Gonzalez-Gay
}

Ann Rheum Dis 2005;64:1658-1659. doi: 10.1136/ard.2004.034363

A 38 year old female owner of a fashion shop presented at the rheumatology outpatient clinic because of intense pain and nodular lesions in her hands (fig lA). She had a 1 year history of pain and multiple small intradermal deposits, with drainage of white chalky material. She had been initially considered to have an infection owing to the presence of a pyogenic pustule. Because of this, she had been treated with several courses of antibiotics (oral cloxacillin for 2 weeks and then oral amoxicillin plus clavulanic acid for another 2 weeks) draining a thick material, but not frank pus. At the outpatient clinic a needle aspiration obtained a thick white matter. Cultures were sterile and the material contained numerous monosodium urate crystals. She was diagnosed as having intradermal tophaceous gout.

Tophaceous gout is an unusual feature in a young woman. ${ }^{12}$ In these cases a careful search for secondary conditions needs to be carried out. Our patient had a 3 year history of intense fear of gaining weight or becoming fat, subjective disturbance in her body shape "feeling fat", and 1 year before diagnosis she had amenorrhoea and constipation. She also admitted excessive ingestion of laxatives and diuretic abuse. At diagnosis her body fat was undetectable, and the bones protruded through the skin. Her height was $163 \mathrm{~cm}$ and her weight $55 \mathrm{~kg}$ (body mass index was 20.7). Our patient had a medical history consistent with anorexia nervosa.

Laboratory determinations disclosed anaemia (haemoglobin $99 \mathrm{mg} / \mathrm{l})$, leucocytosis $\left(17 \times 10^{9} / \mathrm{l}\right)$, and $402 \times 10^{9}$ platelets/ 1. A routine blood biochemistry profile yielded glucose
$5.9 \mathrm{mmol} / \mathrm{l}$, creatinine $90 \mu \mathrm{mol} / \mathrm{l}$, urea nitrogen $16.0 \mathrm{mmol} / \mathrm{l}$, sodium $138 \mathrm{mmol} / \mathrm{l}$, potassium $2.2 \mathrm{mmol} / \mathrm{l}$, and uric acid $456 \mu \mathrm{mol} / \mathrm{l}$. The 24 hour urate clearance was clearly low $(3.2 \mathrm{ml} / \mathrm{min})$ and the 24 hour uric acid excretion was $1.6 \mathrm{mmol} /$ day. Thyroid stimulating hormone and thyroxine (T4) levels were normal. Follicle stimulating hormone (14.8 $\mathrm{U} / \mathrm{l})$, luteinising hormone $(8.2 \mathrm{U} / \mathrm{l})$, and $17 \beta$-estradiol ( $150 \mathrm{pmol} / \mathrm{l})$ were within normal ranges. Purine enzyme studies, including hypoxanthine guanine phosphoribosyl transferase, adenine phosphoribosyl transferase, and phosphoribosyl pyrophosphate synthetase, were normal. Evaluation showed glucose-6-phosphatase deficiency was also normal. There was no history of exposure to lead. Treatment with allopurinol was started and 9 months later total resolution of the intradermal tophi was achieved (fig 1B).

A number of unusual cutaneous manifestations of chronic gout have been reported. ${ }^{3}$ As observed in our patient, deposition of urate crystals in the skin can take the form of intradermal, superficial collections of white tophaceous material resembling pus. Aspiration of the nodular collection demonstrating monosodium urate is the preferred technique to achieve a precise diagnosis. ${ }^{12}$

In cases such as our patient, once a diagnosis of chronic tophaceous gout is made, a secondary condition must be excluded. ${ }^{12}{ }^{4}$ Premenopausal gout is commonly associated with obesity, renal insufficiency, and hypertension. However, Hayem et al report three cases of tophaceous gout affecting premenopausal women and the only precipitating factor was
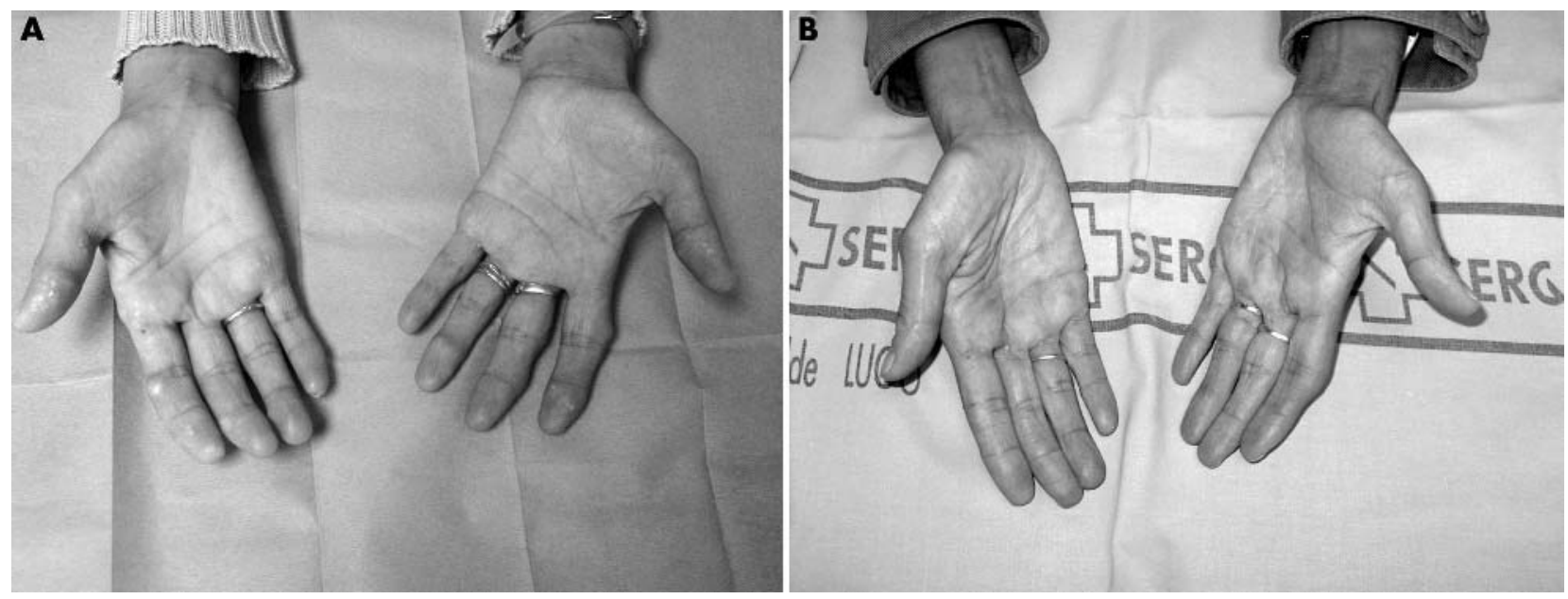

Figure 1 (A) Superficial collections of white tophaceous chalky material resembling pus. (B) Complete resolution of hand lesions after allopurinol treatment. A colour version of the figure can be found at http://www. annrheumdis. com/supplemental 
the overuse of furosemide. In their cases, the authors highlighted the importance of a careful search for hidden diuretic abuse. ${ }^{4}$ Uric acid is primarily excreted by the kidney, and certain drugs including diuretic agents can reduce the excretion of uric acid. No specific tests exist for a diagnosis of anorexia nervosa. Cultural issues, occupation, and body image are important factors in this condition. ${ }^{5}$ In our case a dysmorphophobia led to inadequate nutrition and an excessive consumption of diuretics. With this case we would like to emphasise that in Western countries, where culture and body image play an important role in eating disorders, ${ }^{6}$ the diagnosis of tophaceous gout in a young woman should require a psychological evaluation to exclude a medical history consistent with anorexia nervosa.

A colour version of fig 1 can be found at http:// www.annrheumdis.com/supplemental
Authors' affiliations

C Garcia-Porrua, M A Gonzalez-Gay, Division of Rheumatology, Hospital Xeral-Calde, Lugo, Spain

C Canedo, Division of Psychiatry, Hospital Xeral-Calde, Lugo, Spain

R Argueso, Division of Endocrinology. Hospital Xeral-Calde, Lugo, Spain

Correspondence to: Dr C Garcia-Porrua, Rheumatology Division, Hospital Xeral-Calde, Lugo, c) Dr. Ochoa s/n 27004, Lugo, Spain; cgporrua@hotmail.com

Accepted 3 April 2005

\section{REFERENCES}

Pascual E, Pedraz T. Gout. Curr Opin Rheumatol 2004;16:282-6.

2 Rott KT, Agudelo CA. Gout. JAMA 2003;289:2857-60.

3 Fam AG, Assaad D. Intradermal urate tophi. J Rheumatol 1997;24:1126-31

4 Hayem G, Delahousse M, Meyer O, Palazzo E, Chazerain P, Kahn MF.

Female premenopausal tophaceous gout induced by long-term diuretic abuse $J$ Rheumatol 1996;23:2166-7.

5 Dorian L, Garfinkel PE. Culture and body image in Western society. Eat Weight Disord 2002;7:1-19.

6 Fairburn CG, Harrison PJ. Eating disorders. Lancet 2003;361:407-16.

\section{Treatment of chronic plantar fasciitis with botulinum toxin A: an open case series with a 1 year follow up}

\section{R Placzek, G Deuretzbacher, F Buttgereit, A L Meiss}

$\mathrm{P}$

lantar fasciitis, a special type of a soft tissue rheumatic syndrome, is a common painful condition which often becomes chronic. Its aetiopathology is not completely understood. ${ }^{1}$ Being over weight and standing work are regarded as predisposing factors. ${ }^{2}$ Microtrauma, nerve entrapment (Baxter's nerve), or limited ankle dorsiflexion are thought to be responsible. ${ }^{3}$

Most patients can be treated with physical therapy, local glucocorticoid injections, insoles, acupuncture, and extracorporeal shock wave therapy. ${ }^{56}$ However, this treatment cannot improve the pain in all cases and can require a lot of time on the part of both patient and therapist. Surgery is controversial and should be restricted to patients who do not respond to conservative treatment.

It is not yet clear whether treatment of chronic plantar fasciitis with botulinum toxin A (Btx-A) works by causing muscle paresis or by analgesic/anti-inflammatory effects, or both. A combined effect may occur-namely, ( $a$ ) induction of paresis of the muscles originating at the medial calcaneal process and $(b)$ occurrence of direct analgesia owing to its anti-nociceptive and anti-inflammatory properties. ${ }^{7-10}$

In this pilot study here the effect of a single injection of Btx-A was studied in an open case series.

Nine patients with chronic plantar fasciitis (five women, four men, mean (SD) age 55 (9.5) years) were treated with Btx-A. The average disease period was 14 months (range 236). Patients were selected according to the inclusion and exclusion criteria of an already planned multicentre study (table 1).

Btx-A (500 units; Dysport, IPSEN Pharma, Ettlingen, Germany) was dissolved in $5.0 \mathrm{ml}$ injection solution ( $0.9 \%$ saline), and $2.0 \mathrm{ml}$ (200 units) were injected subfascially in four different directions through one injection puncture into the painful area at the origin of the plantar fascia. The procedure was always performed by the first author.

The following measurements were recorded at weeks 2, 6, 10, 14, 26, 39, and 52:

- Greatest pain during the past 48 hours using a visual analogue scale (VAS), $0-10$

- Pain at rest during the past 48 hours using a VAS, 0-10

- Measurement of muscle force using Brunner's method, scale $0-5$, for

- Extension and flexion of the great toe

- Extension and flexion of the foot

- Pronation and supination of the foot

- Pain progression stage using Gerbershagen's score (Mainz Pain Staging System) at first visit (injection) and final examination (week 52).

Statistical analysis was performed using Wilcoxon's test. Two weeks after injection a pronounced and statistically significant reduction of pain at rest during the past 48 hours was observed using a VAS (fig 1). The maximum pain during the past 48 hours was reduced to the same extent $(\mathrm{p}<0.015)$.

The recorded Mainz Pain Staging System (1-3) at injection and at week 52 showed a decrease from an average stage of 1.56 to 1.00 . It is certainly not a specific tool for staging chronicity in plantar fasciitis, but we aimed at making a general statement on the course of the disease. Undesirable effects such as muscle weakness or systemic reactions were not seen. Our patients were satisfied not only by the pain 
Table 1 Main inclusion and exclusion criteria of a planned multicentre study which were relevant for the selection of our nine patients

Inclusion criteria

- Written informed consent to participate in the study

- Age: at least 18 years

- Chronic plantar fasciitis (duration of the disease at least 4 months*)

- At least two unsuccessful conservative treatments

- At least four points on a VAS (0-10) for maximum pain during the past 48 hours

- On physical examination no evidence of other musculoskeletal diseases

- Diagnostic imaging within the previous 6 months (plain radiography, CT, MRI)

- No treatment with aminoglycoside antibiotics during the first 3 months of follow up

Exclusion criteria

- Participation in a clinical trial within the past 3 months

- Simultaneous participation in another clinical trial

- Prior treatment with Btx-A (that is only de novo patients)

- Surgical pretreatment in the affected area of the foot

- Known allergy or antibodies to Btx-A

- Presence of a rheumatoid disease

- Known muscle diseases or disturbance of neuromuscular transmission

- Treatment with coumarin or hereditary disturbance of coagulation

- Pregnancy or lactation

- Women of childbearing age without adequate contraceptive protection

- Serious accompanying diseases, particularly of the heart, liver, kidneys, and systemic diseases

- Abuse of alcohol or drugs

- Concomitant prohibited drugs (particularly drugs for pain)

- Concomitant prohibited treatment: local injections in the 2 weeks before and during the study

- Depression (also ingestion of antidepressants)

- Current inability to work having lasted for more than 3 months owing to plantar fasciitis

- Current compensation claims because of plantar fasciitis

- Current application for a pension or desire for a pension

*In one patient a duration of the disease of only 2 months was accepted.

$\mathrm{VAS}$, visual analogue scale; $\mathrm{CT}$, computed tomography; $\mathrm{MRI}$, magnetic resonance imaging

relief but also that only one injection was needed. The treatment is cost effective compared with repeated physical treatment, acupuncture, or extracorporeal shock wave therapy.

Our results thus suggest that a single injection of 200 units Btx-A (Dysport) may be a possible treatment for patients with chronic plantar fasciitis. This level IV study may yield the database for a power analysis of a double blind, placebo controlled multicentre study (in preparation).

Authors' affiliations

R Placzek, F Buttgereit, Charité University Medicine, Berlin, Germany G Deuretzbacher, A L Meiss, University Hospital, Hamburg-Eppendorf, Germany

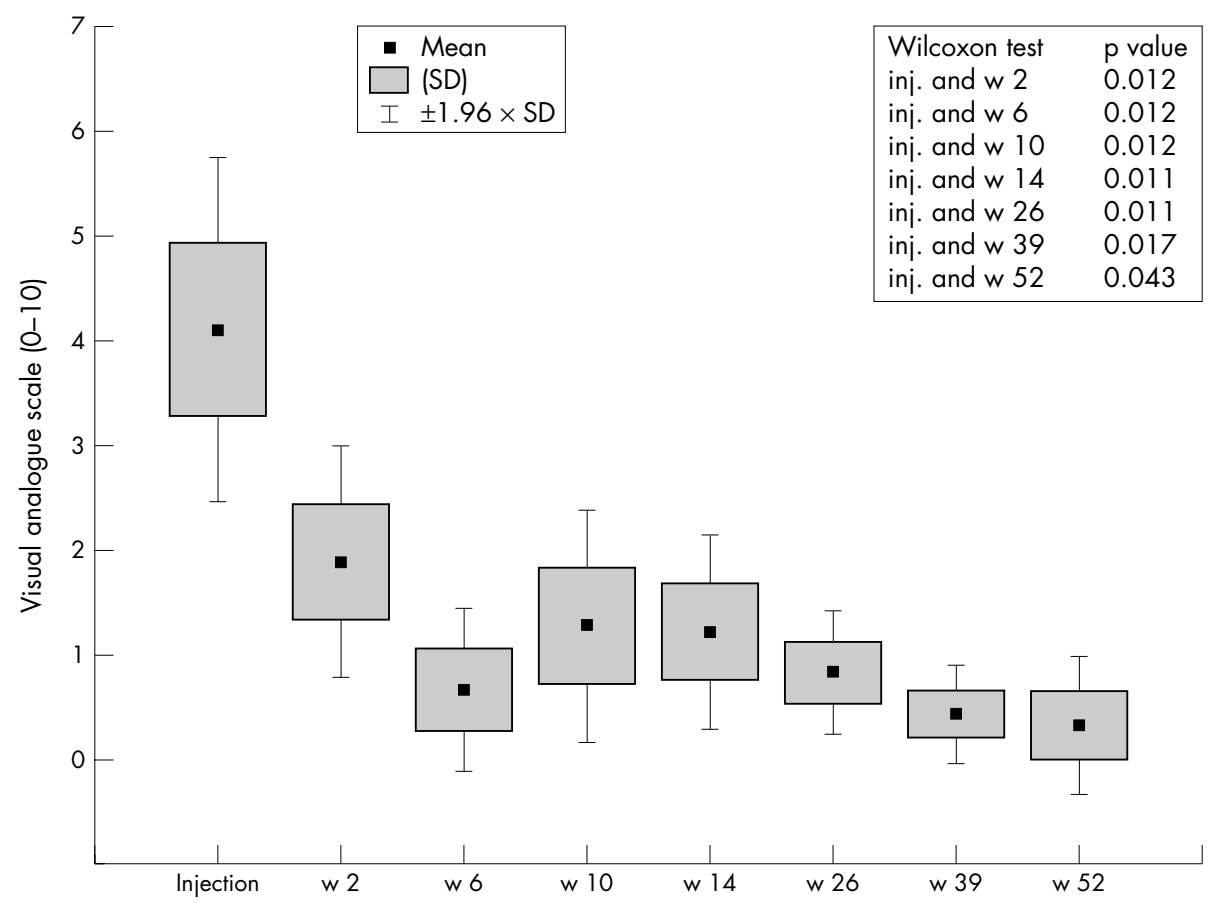

Figure 1 Pain at rest during the previous 48 hours on a VAS, $0-10$. The significance level ( $p$ value) is shown in the table (top right). 
Correspondence to: Dr R Placzek, Centrum für Muskuloskeletale Chirurgie, Charité Universitätsmedizin, Berlin, Campus VirchowKlinikum, Augustenburger Platz 1, 13353 Berlin, Germany; richard. placzek@charite.de

Accepted 3 April 2005

\section{REFERENCES}

1 Schepsis AA, Leach RE, Gorzyca J. Plantar fasciitis. Etiology, treatment, surgical results, and review of the literature. Clin Orthop 1991;266:185-96.

2 Hill JJ Jr, Cutting PJ. Heel pain and body weight. Foot Ankle 1989:9:254-6.

3 Baxter DE, Thigpen CM. Heel pain-operative results. Foot Ankle 1984;5:16-25.
4 Riddle DL, Pulisic M, Pidcoe P, Johnson RE. Risk factors for plantar fasciitis: a matched case-control study. J Bone Joint Surg Am 2003;85:872-7.

5 Gill LH, Kiebzak GM. Outcome of nonsurgical treatment for plantar fasciitis. Foot Ankle Int 1996;17:527-32.

6 Ogden JA, Alvarez RG, Levitt RL, Johnson JE, Marlow ME. Electrohydraulic high-energy shock-wave treatment for chronic plantar fasciitis. J Bone Joint Surg Am 2004;86:2216-28.

7 Chalkiadaki A, Rohr UP, Hefter H. [Early pain reduction in the treatment of spasticity after a single injection of botulinum A toxin]. Dtsch Med Wochenschr $2001 ; 126: 1361-4$

8 Gobel H, Jost WH. [Botulinum toxin in specific pain therapy]. Schmerz 2003;17:149-65.

9 Kelm S, Gerats G, Chalkiadaki A, Hefter H. [Reduction of pain and muscle spasms by botulinum toxin A]. Nervenarzt 2001;72:302-6.

10 Cui M, Khanijou S, Rubino J, Aoki KR. Subcutaneous administration of botulinum toxin A reduces formalin-induced pain. Pain 2004;107:125-33.

\title{
Bilateral hydropneumothoraces in a patient with pulmonary rheumatoid nodules during treatment with methotrexate
}

\author{
N Steeghs, T W J Huizinga, H Dik
}

Ann Rheum Dis 2005;64:1661-1662. doi: 10.1136/ard.2004.032011

E xtra-articular manifestations in rheumatoid arthritis (RA), in particular rheumatoid nodules, are common. The most common pulmonary manifestations are pleural abnormalities and interstitial lung disease. ${ }^{1}$ Nodules observed on a chest $x$ ray examination are a well known diagnostic dilemma in patients with RA, given the differential diagnosis of malignancy and rheumatoid nodules. Spontaneous pneumothorax secondary to pulmonary rheumatoid nodules is an uncommon complication of RA. ${ }^{23}$

A 73 year old female patient was admitted for cough, fever, and dyspnoea. She had had seropositive RA for 15 years, and had a history of chronic bronchitis, heart failure, diabetes mellitus, and hypothyroidism. She had been treated for 1 year with prednisone $7.5 \mathrm{mg} /$ day and methotrexate (MTX), for active arthritis. The MTX dose was raised to $12.5 \mathrm{mg} /$ week a month before presentation.

On admission, the patient was dyspnoeic and had a temperature of $39.3^{\circ} \mathrm{C}$. She had clinical features of a right sided pneumothorax and destructive joint disease. No evidence of active arthritis or subcutaneous rheumatoid nodules was seen. The erythrocyte sedimentation rate was $73 \mathrm{~mm} / \mathrm{lst} \mathrm{h}$ and the white blood cell count $20.3 \times 10^{9} / 1$. A chest $x$ ray examination demonstrated a hydropneumothorax of the right lung.

Drainage by a chest tube produced chylous fluid and air leakage. Antibiotic treatment was started and the temperature normalised. Microbiological cultures and extensive examinations to locate an infection were all negative. A computed tomographic scan (CT scan) showed bilateral hydropneumothoraces with subpleural nodes and thickened pleura visceralis on the right side (fig 1). Ten days after admission the MTX was discontinued and steroid treatment was increased ( $30 \mathrm{mg} /$ day) to control extra-articular disease (the nodulosis). The bilateral hydropneumothorax persisted. A week later a vigorous subcutaneous emphysema developed. A larger diameter chest tube was placed in the right pleural space. Continuing air leakage persisted. Thoracotomy was considered not to be an option in her condition. Ulcers and necrosis of the foot necessitated partial amputation of her right foot. Secondary infections occurred. Two months after admission the patient died.

Postmortem analysis showed bilateral hydropneumothoraces, with multiple subpleural nodules on both sides.
The largest nodule, $2 \mathrm{~cm}$, was located in the right lower lobe and had disrupted the pleura visceralis at that place.

The causes of pleural effusion are various, but combination with a pneumothorax narrows the differential diagnosis. In patients with RA who develop bilateral hydropneumothoraces, extra-articular disease (for example, rheumatoid nodules) should be considered as the cause.

Pleural effusions develop as an inflammatory response to the presence of subpleural nodules. Pneumothoraces occur as a result of cavitation of necrobiotic nodules that rupture to the pleural space, as in our patient, and are rare complications of RA. ${ }^{3}$ The incidence of pulmonary nodules is $<1 \%$ on chest $x$ ray examination, and about $25 \%$ on high resolution CT scan. ${ }^{1}$ They are associated, in most cases, with longstanding seropositive RA, the male sex, and subcutaneous rheumatoid nodules.

Previous reports suggest that MTX might be involved in exacerbating extra-articular manifestations of RA. ${ }^{4}$ These

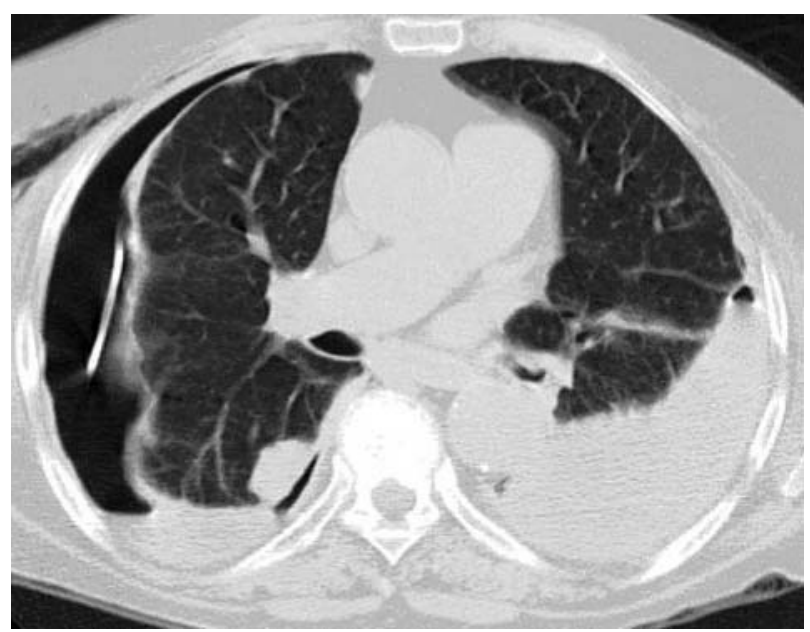

Figure 1 Thoracic CT scan showing bilateral pneumothoraces and pleural effusions. A large pulmonary rheumatoid nodule is located in the right lower lobe. A chest tube is placed in the right pleural space. The visceral pleural membrane is markedly thickened. 
reports describe exacerbation of subcutaneous rheumatoid nodules; pulmonary nodules were not investigated. A small number of case studies describe patients with pulmonary nodules, developing pneumothorax after the initiation or augmentation of MTX treatment, as in our patient. ${ }^{5}$ No definitive relationship could be established.

Given the fact that the cause of a pneumothorax can be extra-articular rheumatoid disease, one may consider that more intensive immunosuppressive treatment should be initiated earlier in patients with RA and pneumothorax due to necrosis in a pulmonary nodule. We recommend that necrosis of a pulmonary nodule is considered in the differential diagnosis of pleural effusion and pneumothorax in patients with RA. Given the adverse effects of cyclophosphamide and prednisone treatment, other causes should be excluded.

\section{Authors' affiliations}

N Steeghs, Department of Internal Medicine, Rijnland Hospital, Leiderdorp, the Netherlands

T W J Huizinga, Department of Rheumatology, Leiden Medical Centre,
Leiden, the Netherlands

H Dik, Department of Pulmonary Medicine, Rijnland Hospital, Leiderdorp, the Netherlands

Correspondence to: Mrs N Steeghs, Department of Internal Medicine C1-R41, University Hospital, Albinusdreef 2, PO box 9600, 2300 RC Leiden, The Netherlands; n.steeghs@lumc.nl

Accepted 3 April 2005

\section{REFERENCES}

1 Tanove LT. Pulmonary manifestations of rheumatoid arthritis. Clin Chest Med. 1998;19: 667-85, viii.

2 Ayzenberg $\mathrm{O}$, Reiff DB, Levin L. Bilateral pneumothoraces and pleural effusions complicating rheumatoid lung disease. Thorax 1983;38:159-60.

3 Saravana S, Gillott T, Abourawi F, Peters M, Campbell A, Griffith S. Spontaneous pneumothorax: an unusual presentation of rheumatoid arthritis. Rheumatology (Oxford) 2003;42:1415-16.

4 Kerstens PJ, Boerbooms AM, Jeurissen ME, Fast JH, Assmann KJ, van de Putte LB. Accelerated nodulosis during low dose methotrexate therapy for rheumatoid arthritis. An analysis of ten cases. J Rheumatol 1992;19:867-71.

5 Gotsman I, Goral A, Nusair S. Secondary spontaneous pneumothorax in a patient with pulmonary rheumatoid nodules during treatment with methotrexate. Rheumatology (Oxford) 2001;40:350-1.

\section{Seasonal pattern in the onset of polymyalgia rheumatica}

\section{F Perfetto, A Moggi-Pignone, A Becucci, F Cantini, M Di Natale, R Livi, A Tempestini, $M$ Matucci-Cerinic}

$\mathrm{T}$ he aetiology of polymyalgia rheumatica (PMR) is unknown, but its sudden onset and the wide variation in incidence reported from various parts of the world suggest the existence of an environmental agent or genetic factors, or both. $^{12}$ Interestingly, epidemiological studies showed a regular cyclical pattern of incidence of $\mathrm{PMR}^{1-3}$ whereas others failed to confirm any seasonal trend. ${ }^{4-6}$

To evaluate the seasonal distribution in the onset of symptoms of PMR, this retrospective study considered 201 patients (mean age 72.6 years; 126 women, 75 men) with a diagnosis of $\mathrm{PMR}^{7}$ seen by rheumatology units of the Prato (125 patients) and Florence Hospitals (76 patients), Italy, from January 1992 to December 2002. All patients were identified by searching hospital (74 patients) or ambulatory records ( 127 patients). In 21 patients, PMR was associated with giant cell arteritis (GCA).

Differences between seasonal incidence were assessed by the $\chi^{2}$ test and by the single cosinor analysis. The parameters calculated with the cosinor procedure were the MESOR (the rhythm adjusted mean over the time period analysed), amplitude (half the distance between the absolute maximum and minimum of the fitted curve), and acrophase (peak time of rhythmic change). Significance was defined as $p<0.05$.

In 71 patients symptoms started in winter, 49 in spring, 33 in summer, and 48 in autumn. The $\chi^{2}$ test showed that the frequency of onset of PMR was significantly $(p<0.001)$ increased in winter for all the patients and also for subsets by sex (men, $\mathrm{p}<0.01$; women, $\mathrm{p}<0.04$ ) and age (age $<75$, $\mathrm{p}<0.001$; age $>75, \mathrm{p}>0.001$ ). Rhythm analysis (table 1 ) identified a circannual variation in the occurrence of PMR, with a significant $(\mathrm{p}<0.001)$ peak in January. A similar circannual pattern was also identified for subsets by age (age
$<75, \mathrm{p}<0.001$; age $>75, \mathrm{p}<0.01)$ and $\operatorname{sex}(\mathrm{p}=0.03)$ (table 1$)$ No rhythm was detected in patients with PMR/GCA.

This study shows a significant winter periodicity in the onset of PMR. These results are in agreement with many previous reports ${ }^{1-3}$ but contrast with others ${ }^{4-6}$ that failed to demonstrate seasonality. Differences in the composition of the group (such as high proportion of patients with PMR/ GCA), size of the group, geographical location (northern versus southern Europe), and statistical procedure may explain these discrepancies. Unlike this study, previous reports checked the statistical significance of the time effect on the onset of symptoms only by the $\chi^{2}$ test. That test, however, only indicates whether the counts are different in a different season of the year without necessarily implying the presence of a circannual cycle, and it gives no information as to its timing. On the contrary, the cosinor method provides a better chronobiological analysis and yields rhythmic characteristics such as the MESOR, amplitude, and acrophase, each with its variance estimate.

Two potentially synergistic mechanisms may have a role in the seasonality of PMR. Firstly, the infectious-like onset of PMR suggests a precipitating environmental factor as one of the causes, and a close temporal relationship between epidemics of Mycoplasma pneumoniae, Chlamydia pneumoniae, and parvovirus B19 and peaks of cases of PMR/GCA has been reported. ${ }^{12}$ However, reports of material with an infectious origin in temporal arteries have not been corroborated, ${ }^{8}{ }^{9}$ and Peris found no relationship between the onset of PMR and parvovirus B19 infection. ${ }^{6}$ Secondly, some authors have reported seasonal variation of the immune system and inflammatory responsiveness. ${ }^{10}$ These seasonal changes, when associated with several unknown infectious agents, may 
Table 1 Circannual rhythm parameters of single cosinor analysis fitted to monthly data of occurrence of PMR/GCA

\begin{tabular}{|c|c|c|c|c|c|c|c|}
\hline Group & No & PR & $\begin{array}{l}\text { MESOR } \\
\text { Mean (SEM) }\end{array}$ & $\begin{array}{l}\text { Amplitude } \\
\text { Mean (SEM) }\end{array}$ & $\begin{array}{l}\text { Peak (degree) } \\
\text { Mean (SEM) }\end{array}$ & Peak (month*) & p Value \\
\hline Total & 201 & 83.0 & $16.7(0.7)$ & 7.09 (1.07) & $-26.7(8.6)$ & January & $<0.001$ \\
\hline Age $<75$ years & 114 & 83.3 & $9.5(0.45)$ & $4.27(0.64)$ & $-357.2(8.5)$ & December & $<0.001$ \\
\hline Age $>75$ years & 87 & 62.6 & $7.2(0.67)$ & $3.65(0.94)$ & $-58.6(14.8)$ & February & $<0.01$ \\
\hline Women & 126 & 53.3 & $10.48(0.8)$ & $3.61(1.13)$ & $-22.4(17.8)$ & January & $<0.03$ \\
\hline Men & 75 & 54.2 & $6.23(0.76)$ & $3.5(1.08)$ & $-31.2(17.5)$ & January & $<0.03$ \\
\hline PMR & 180 & 67.5 & $14.72(0.95)$ & $5.83(1.35)$ & $-29.7(13.2)$ & January & $<0.005$ \\
\hline GCA & 21 & 1.5 & $2.43(0.44)$ & $0.17(0.64)$ & $-291.3(215.9)$ & $?$ & 0.9 \\
\hline
\end{tabular}

$\mathrm{PR}$, percentage of overall variability of data about the arithmetic mean attributable to the fitted rhythmic function; MESOR, the rhythm adjusted mean over the time period analysed; Amplitude, half of peak to trough of rhythmic change; Acrophase, peak time of rhythmic change expressed in (negative) degrees, with $360^{\circ}=$ period length ( 1 year $=8766$ hours) and $0^{\circ}=$ midnight of 22 December before starting the study; $p$, probability value resulting from the $F$ statistic used to test the hypothesis of 0 amplitude (no rhythm).

${ }^{*}$ Each month $=30^{\circ}$.

increase the susceptibility to develop some diseases, including PMR. Further longitudinal studies conducted on larger samples and in other countries at different latitudes are needed.

\section{Authors' affiliations}

F Perfetto, A Moggi-Pignone, A Becucci, R Livi, A Tempestini, M Matucci-Cerinic, Department of Medicine, Rheumatology Division, University of Florence, Italy

F Cantini, M Di Natale, 2nd Division of Medicine-Rheumatology Unit, Ospedale di Prato, Italy

Correspondence to: Dr F Perfetto, Department of Medicine, Rheumatology Division, University of Florence, Viale Pieraccini 18, 50139 Florence, Italy; perfetto@unifi.it

Accepted 28 March 2005

\section{REFERENCES}

1 Salvarani C, Gabriel SE, O'Fallon WM, Hunder GG. The incidence of giant cell arteritis in Olmsted County, Minnesota: apparent fluctuations in a cyclic pattern. Ann Intern Med 1995;123:192-4.
2 Elling $\mathrm{P}$, Olsson AT, Elling $\mathrm{H}$. Synchronous variation of the incidence of temporal arteritis and polymyalgia rheumatica in different regions of Denmark: association with epidemics of Mycoplasma pneumoniae infection. J Rheumatol 1996;23:112-19.

3 Cimmino MA, CaporaliR, Montecucco CM, Rovida S. A seasonal pattern in the onset of polymyalgia rheumatica. Ann Rheum Dis 1990;49:521-3.

4 Duhaut $P$, Pinède $L$, Bornet $H$, Demolombe-Raguè, Dumontet $C$, Ninet $J$, et al. Biopsy proven and biopsy negative temporal arteritis: differences in clinical spectrum at the onset of the disease. Groupe de Recherche sur l'Arterite a Cellules Geantes. Ann Rheum Dis 1999;58:335-41.

5 Narvaez J, Clavaguera MT, Nolia-Sole JM, Valverde GJ, Roig, ED. Lack of association betwwen infection and onset of PMR. J Rheumatol 2000;27:953-7.

6 Peris $\mathbf{P}$. Polymyalgia rheumatica is not seasonal in pattern and is unrelated to parvovirus B19 infection. J Rheumatol 2003;30:2624-6.

7 Bird HA, Esselinckx W, Dixon AS, Mowat AG, Wood PH. An evaluation of criteria for polymyalgia rheumatica. Ann Rheum Dis 1979;38:434-9.

8 Helweg-Larsen J, Tarp B, Obel N, Baslund B. No evidence of parvovirus B19, Chlamidya pneumoniae or human helper infection in temporal artery biopsies in patients with giant cell arteritis. Rheumatology (Oxford) 2002;41:445-9.

9 Salvarani C, Farnetti E, Casali B, Nicoli D, Wenlan L, Bajocchi GL, et al. Detection of parvovirus B19 DNA by polymerase chain reaction in giant cell arteritis: a case-control study. Arthritis Rheum 2002;46:3099-101

10 Haus E, Smolensky MH. Biologic rhythm in the immune system. Chronobiol Int 1996;16:581-622.

\section{FDG-PET/CT scan of inflammatory spondylodiscitis lesions in ankylosing spondylitis, and short term evolution during anti-tumour necrosis factor treatment}

\section{Wendling, O Blagosklonov, G Streit, G Lehuédé, E Toussirot, J-C Cardot}

Ann Rheum Dis 2005;64:1663-1665. doi: 10.1136/ard.2005.040345

$\mathrm{P}$ ositron emission tomography/computed tomography (PET/CT scan) represents a new molecular imaging modality using physiological tracers to assess a lesion's metabolic state. $\left[{ }^{18}\right.$ F]Fluorodeoxyglucose (FDG) PET appears to be very good for the evaluation of cancer lesions and potentially useful in inflammatory rheumatic disorders, but there is scant information in ankylosing spondylitis (AS).

We evaluated an FDG-PET/CT scan $(4 \mathrm{MBq} / \mathrm{kg}$ FDG injection, whole body acquisition using a Siemens Biograph Duo device, volumic fixation values are expressed as standardised uptake values (SUVs)), in patients with AS (revised New York criteria) with magnetic resonance imaging (MRI) documented lumbar aseptic spondylodiscitis (discovertebral biopsy in two patients) requiring anti-tumour necrosis factor (TNF) treatment. A second PET evaluation
Table 1 Characteristics of the patients

\begin{tabular}{llll}
\hline & \multicolumn{3}{l}{ Patient No } \\
\cline { 2 - 4 } Characteristics & $\mathbf{1}$ & $\mathbf{2}$ & $\mathbf{3}$ \\
\hline Age (years) & 47 & 36 & 44 \\
Sex & Male & Male & Male \\
AS duration (years) & 18 & 15 & 6 \\
HLA- B27 & + & no & + \\
Localisation & L3-4 & L4-5 & L4-5 \\
Biopsy & + & ND & + \\
Anti-TNF treatment & Infliximab & Etanercept & Etanercept \\
& $5 \mathrm{mg} / \mathrm{kg}$ & $\begin{array}{l}25 \mathrm{mg} \text { twice/ } \\
\text { week }\end{array}$ & $\begin{array}{l}25 \mathrm{mg} \text { twice/ } \\
\text { week }\end{array}$ \\
\hline
\end{tabular}


Table 2 Evaluation of several variables before, during, and after treatment

\begin{tabular}{lllllll}
\hline \multicolumn{7}{l}{ Time of valuation (week) } \\
\cline { 2 - 7 } Variables & $\mathbf{0}$ & $\mathbf{6}$ & $\mathbf{0}$ & $\mathbf{8}$ & $\mathbf{0}$ & $\mathbf{6}$ \\
\hline ESR (mm/1st h) & 79 & 35 & 26 & 4 & 2 & 15 \\
CRP (mg/l) & 33 & 7 & 20 & 2 & 5 & 39 \\
BASDAl (0-10) & 6.8 & 5.5 & 2.4 & 0.2 & 5.2 & 5.6 \\
BASFI (0-10) & 9.1 & 8.5 & 2.8 & 0.3 & 4.7 & 5.4 \\
BAS-G (0-10) & 9.6 & 7.7 & 5.5 & 0.7 & 6.3 & 6.0 \\
Pain (0-10) & 9.3 & 6.3 & 3.2 & 0.7 & 7.5 & 4.7 \\
FFD (cm) & 62 & 54 & 18 & 5 & 34 & 30 \\
Schober $(\mathrm{cm})$ & 1 & 2 & 2 & 4 & 3 & 3 \\
CE $(\mathrm{cm})$ & 2.5 & 5 & 3 & 6 & 5 & 5 \\
OWD $(\mathrm{cm})$ & 6 & 4 & 0 & 0 & 0 & 0 \\
SUV max & 4.08 & 2.67 & 2.84 & 2.44 & 2.88 & 2.49 \\
SUV min & 2.05 & 1.34 & 1.42 & 1.22 & 1.44 & 1.26 \\
SUV mean & 2.61 & 1.74 & 1.84 & 1.54 & 1.78 & 1.64 \\
SD & 0.41 & 0.33 & 0.30 & 0.25 & 0.30 & 0.30 \\
Volume $\left(\mathrm{cm}^{3}\right)$ & 10.81 & 10.63 & 41.54 & 10.94 & 37.99 & 25.89 \\
\hline
\end{tabular}

ESR, erythrocyte sedimentation rate; CRP, C reactive protein; BASDAl, Bath Ankylosing Spondylitis Disease Activity Index; BASFI, Bath Ankylosing Spondylitis Functional Index; BAS-G, Bath Ankylosing Spondylitis Global; FFD, finger to floor distance; CE, chest expansion; OWD, occiput to wall distance; SUV, standardised uptake value.

was performed at the time of the anti-TNF response assessment, between 6 and 8 weeks of treatment, in parallel with a second MRI examination, and clinical evaluation.

Short time (6-8 weeks) clinical outcome (tables 1 and 2) showed a good response in patient $2(>50 \%$ improvement in all measures), no response in patient 3 (fig 1 ), and incomplete response in patient 1 (20\% improvement in C reactive protein (CRP), pain, metrology).

MRI evolution, without quantification, showed reduction of $\mathrm{T}_{2}$ weighted hypersignal and reduction of gadolinium enhancement for patients 1 and 2, and absence of modification for patient 3 (without clinical improvement).

FDG-PET/CT imaging showed a reduction of FDG uptake on the spondylodiscitis in all three patients. This reduction was significant in patient 1 (incomplete clinical response), borderline in patient 2 with good clinical response, and not significant in patient 3 (no clinical response). In patient 2 , global FDG uptake heterogeneity in the lumbar spine made measurement difficult (very different measurement volumes between the two evaluations).
Aseptic spondylodiscitis is a classic feature in AS. ${ }^{1}$ An FDGPET/CT scan may be used to explore several inflammatory disorders: vasculitis, ${ }^{23}$ rheumatoid arthritis, ${ }^{4}$ peripheral arthritis $^{5}$ or psoriatic arthritis, ${ }^{6}$ with a good correlation between disease activity and mean SUV.

In our three cases, FDG uptake was evident at the site of discitis, with mean SUVs ranging from 1.8 to 2.6) and reduction after anti-TNF treatment. This reduced uptake may be due to an impairment of local inflammation, or to a cellular effect of the anti-TNF agent on bone marrow. We did not observe a correlation between reduction in FDG uptake and clinical and MRI evolution in these three cases. Nevertheless, the small number of patients does not allow a firm conclusion to be reached. The localisation of uptake, in the disc or the vertebral plate, should be taken into account and may interfere with the target volume and evaluation of the region of interest, especially when uptake is moderate and diffuse, as in our second case. This may be a limitation of this imaging technique in AS when the various pathophysiological

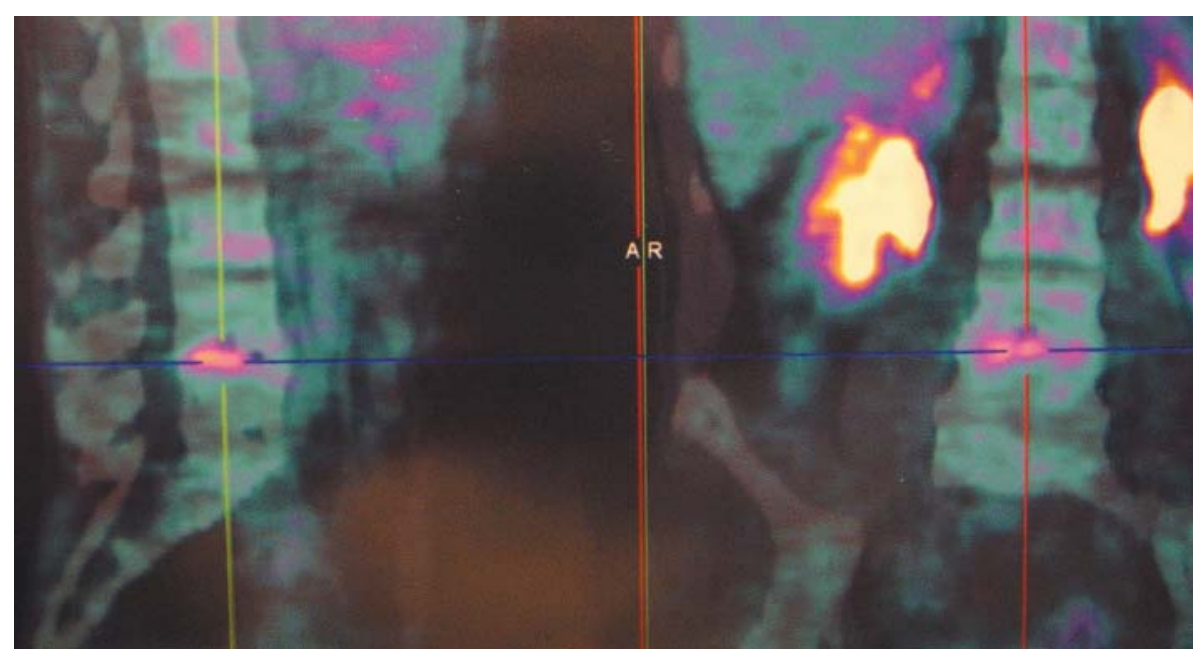

Figure 1 FDG-PET imaging of an L4-5 spondylodiscitis (patient 3, week 0). 
mechanisms leading to aseptic discitis in AS are taken into account. $^{1}$

In infectious spondylodiscitis, this technique proved its usefulness in topographic and differential diagnosis. ${ }^{78}$ Schmitz et al reported 12 cases of biopsy proven infectious spondylitis, with an initial mean (SD) SUV of 7.5 (3.8), and significant reduction after an 8 week treatment (mean SUV $1.75){ }^{8}$

This preliminary study underlines the potential interests and limitations of an FDG-PET/CT scan in AS.

\author{
Authors' affiliations \\ D Wendling, G Streit, G Lehuédé, E Toussirot, Department of \\ Rheumatology, University Teaching Hospital, Boulevard Fleming, \\ F-25030 Besançon, France \\ O Blagosklonov, J-C Cardot, Department of Nuclear Medicine, \\ University Teaching Hospital, Boulevard Fleming, F-25030 Besançon, \\ France \\ Correspondence to: Professor D Wendling, \\ daniel.wendling@ufc-chu.univ-fcomte.fr
}

\section{REFERENCES}

1 Langlois S, Cedoz JP, Lohse A, Toussirot E, Wendling D. Aseptic discitis in patients with ankylosing spondylitis: a retrospective study of 14 cases. Joint Bone Spine 2005;72:248-53.

2 Moosig F, Czech N, Mehl C, Henze E, Zeuner RA, Kneba M, et al. Correlation between 18-fluorodeoxyglucose accumulation in large vessels and serological markers of inflammation in polymyalgia rheumatica: a quantitative PET study. Ann Rheum Dis 2004:63:870-3.

3 Brodmann M, Passath A, Aigner R, Seinost G, Stark G, Pilger E. F18-FDG-PET as a helpful tool in the diagnosis of giant cell arteritis. Rheumatology (Oxford) 2003;42:1264-6.

4 Beckers C, Ribbens C, André B, Marcelis S, Kaye O, Mathy L, et al. assessment of disease activity in rheumatoid arthritis with 18F-FDG PET. J Nucl Med 2004;45:956-64

5 Roivainen A, Parkkola R, Yli-Kerttula T, Lehikoinen P, Viljanen T, Mottonen T, et al. Use of positron emission tomography with methyl-11C-choline and 218F-fluoro-2-deoxy-D-glucose in comparison with magnetic resonance imaging for the assessment of inflammatory proliferation of synovium. Arthritis Rheum 2003;48:3077-84.

6 Yun M, Kim W, Adam LE, Alnafisi N, Herman C, Alavi A. F-18FDG uptake in a patient with psoriatic arthritis. Imaging correlation with patient symptoms. Clin Nucl Med 2001;26:692-3.

7 Gratz S, Dorner J, Fischer U, Behr TM, Béhé M, Altenvoerde G, et al. 18F-FDG hybrid PET in patients with suspected spondylitis. Eur J Nucl Med 2002;29:516-24.

8 Schmitz A, Risse JH, Grunwald F, Biersack HJ, Schmitt O. Fluorine-18 fluorodeoxyglucose positron emission tomography findings in spondylodiscitis: preliminary results. Eur Spine J 2001;10:534-9.

\title{
Healing of psoriatic skin lesions, and improvement of psoriatic arthritis resistant to immunosuppressive drugs, after infliximab treatment
}

\author{
S N Nikas, P V Voulgari, I P Takalou, P Katsimbri, A A Drosos
}

Ann Rheum Dis 2005;64:1665-1667. doi: 10.1136/ard.2005.036178

D uring recent years, much has been learnt about the immunopathology of psoriasis and psoriatic arthritis (PsA). There has been increasing evidence that proinflammatory cytokines, in particular tumour necrosis factor $\alpha$ $(\mathrm{TNF} \alpha)$, may play a central part in potentiating the inflammatory process. Both $\mathrm{CD} 4+$ and CD8+ $\mathrm{T}$ cells are found in psoriatic lesions. ${ }^{1}$ Thus most of the treatments for psoriasis and PsA are immunosuppressive. ${ }^{2}$ However, there are several patients refractory to treatment in whom blockade of TNF $\alpha$ by anti-TNF $\alpha$ inhibitors may be useful. ${ }^{3}$

Five patients (three male, two female; mean (SD) age 41.0 (3.3) years) with longstanding disease (7.9 (3.7) years) refractory to immunosuppressive drugs and corticosteroids were studied. Although some clinical improvement was seen in their musculoskeletal complaints, psoriasis was poorly controlled, requiring frequent inpatient admissions to hospital.

Patients were treated with intravenous infliximab $(5 \mathrm{mg} /$ $\mathrm{kg}$, infusion time $>2$ hours), in a loading dose of $0,2,6$, and 8 weeks thereafter for a period of 12 months. Patients were fully informed about the treatment and signed an informed consent. The area of skin affected was evaluated by the Psoriasis Area and Severity Index (PASI) score, ${ }^{4}$ while joint involvement was assessed by the Psoriatic Arthritis Responder Criteria (PsARC). ${ }^{5}$ The laboratory evaluation included $\mathrm{C}$ reactive protein (CRP; $\mathrm{mg} / \mathrm{l}$ ) and erythrocyte sedimentation rate (ESR; $\mathrm{mm} / \mathrm{lst} \mathrm{h}$ ). All patients continued to receive the same doses of methotrexate (MTX) and ciclosporin A (CSA) during the study period, while the dose of steroids was tapered according to the patient's response.

Of the five patients, three patients had sacroiliitis (two unilateral and one bilateral, stage III) and asymmetric oligoarthritis; one patient had polyarticular symmetric joint disease; and the other had polyarticular asymmetric joint disease. All patients had extensive plaque psoriasis with erythroderma, in two cases affecting $65-90 \%$ of the body surface area. The clinical response was rapid; after the third infliximab infusion about $90 \%$ of the skin lesions improved in all patients, and after the sixth infusion all patients had complete clinical remission and the skin was clear and healed (fig 1). A significant reduction of the PASI score and improvement of PsARC were noted, which were maintained throughout the study. This clinical improvement was associated with the reduction in the acute phase reactants (table 1). The drug was well tolerated, all patients completed the study and only a few patients had mild adverse events. After the third infusion two patients developed a sore throat, while another developed a urinary tract infection after the sixth infusion. In addition, one patient developed a mild allergic reaction after the third infusion. All patients completed the study and the adverse events resolved without sequelae.

Our observation confirms the results reported by others, ${ }^{6-8}$ who demonstrated a significant improvement in treating patients with PsA with infliximab. Their studies investigated primarily the articular component of the disease and to a lesser extent the cutaneous manifestations. As far as we 

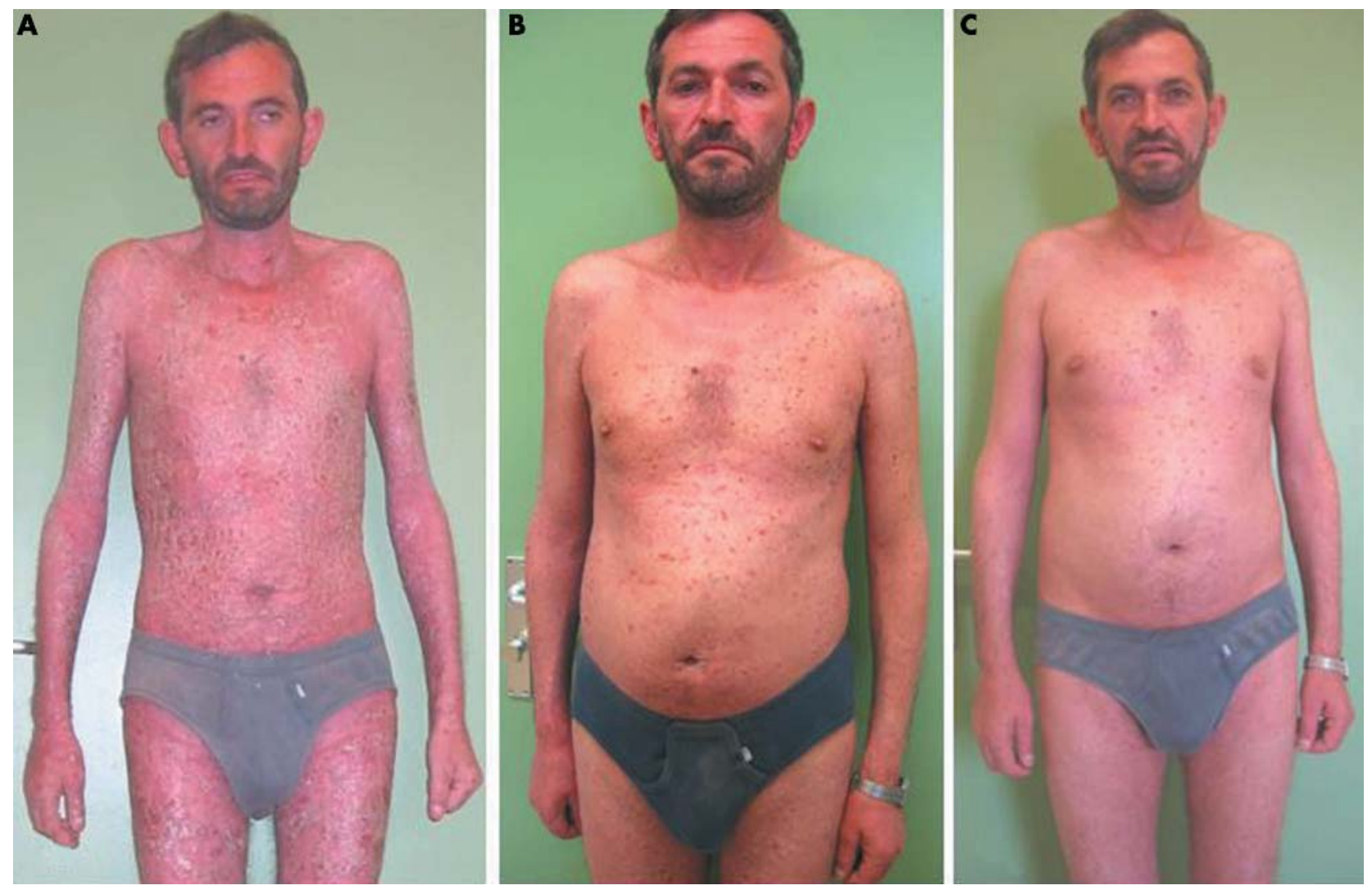

Figure 1 Extensive skin lesions of plaque psoriasis, which coalesce to cover almost the whole of the body surface. The skin lesions are thickened, hyperkeratotic, and erythematous in some regions (A). After the third infliximab infusion about $90 \%$ of the skin lesions were cleared (B), and after the sixth infusion the skin was entirely cleared and healed (C). Reproduced with permission of the patient.

Table 1 Clinical and laboratory changes during infliximab treatment

\begin{tabular}{llllll}
\hline Variables & Week 0 & Week 6 & Week 24 & Week 52 & p Value* \\
\hline Tender joints score & $6.4(4.0)$ & $1.6(1.5)$ & $1.8(1.8)$ & $1.4(1.8)$ & $<0.05$ \\
Swollen joints score & $2.6(1.6)$ & $0.2(0.4)$ & $0.2(0.4)$ & $0.2(0.4)$ & $<0.05$ \\
Patient self assessment & $6.9(2.2)$ & $2.5(2.6)$ & $2.4(1.1)$ & $2.1(1.1)$ & $<0.05$ \\
Physician self assessment & $6.7(2.3)$ & $2.4(1.4)$ & $2.4(1.2)$ & $2.5(1.4)$ & $<0.05$ \\
PASI score & $51.2(14.0)$ & $10.0(1.7)$ & $0.8(0.5)$ & $0.8(0.5)$ & $<0.05$ \\
CRP (mg/l) & $18.4(16.7)$ & $2.6(5.8)$ & $3.0(3.3)$ & $1.6(2.2)$ & $<0.05$ \\
ESR (mm/1st h) & $42.4(18.0)$ & $16.2(12.5)$ & $14.2(8.8)$ & $12.8(7.7)$ & $<0.05$ \\
\hline
\end{tabular}

Results are shown as mean (SD).

*Wilcoxon test for pairs, comparison between week 0 and week 52.

know, our study is the first that shows complete healing of the cutaneous lesions in patients with widespread recalcitrant psoriasis. A significant improvement in the articular component was also noted. Another point to take into consideration is that in our study we used infliximab in combination with MTX, CSA, and steroids. The above combination was demonstrated to be efficacious and safe in treating patients with rheumatoid arthritis and may avoid the formation of human antichimeric antibodies responsible for infliximab inefficacy and adverse drug reactions. ' Finally, the absence of serious adverse events might also be attributed to the small number of patients investigated in this study.

The findings of the present open label study provide evidence that multiple infusions of infliximab are effective and safe in clearing recalcitrant widespread psoriasis. Further larger studies are required to confirm our results.

\section{Authors' affiliations}

S N Nikas, P V Voulgari, I P Takalou, P Katsimbri, A A Drosos,

Rheumatology Clinic, Department of Internal Medicine, Medical School, University of loannina, 45110 loannina, Greece

Correspondence to: Professor A A Drosos, adrosos@cc.uoi.gr

Accepted 11 April 2005

\section{REFERENCES}

1 Bos JD, De Rie MA. The pathogenesis of psoriasis: immunological facts and speculations. Immunol Today 1999;1:40-6.

2 Heydendael VM, Spuls PI, Opmeer BC, de Borgie CA, Reitsma JB, Goldschmidt WF, et al. Methotrexate versus cyclosporine in moderate-tosevere chronic plaque psoriasis. N Engl J Med 2003;349:658-65.

3 Mease PJ. Recent advances in the management of psoriatic arthritis. Curr Opin Rheumatol 2004;16:366-70. 
4 van de Kerkhof PC. The Psoriasis Area and Severity Index and alternative approaches for the assessment of severity: persisting areas of confusion. Br J Dermatol 1997; 137:661-2.

5 Gladman DD, Helliwell P, Mease PJ, Nash P, Ritchlin C, Taylor W. Assessment of patients with psoriatic arthritis: a review of currently available measures. Arthritis Rheum 2004;50:24-35.

6 Chaudhari U, Romano P, Mulcahy LD, Dooley LT, Baker DG, Gottlieb AB. Efficacy and safety of infliximab monotherapy for plaque type psoriasis: a randomized trial. Lancet 2001;357:1842-7.

7 Van Den Bosch F, Kruithof E, Baeten D, Herssens A, de Keyser F, Mielants $\mathrm{H}$, et al. Randomized double-blind comparison of chimeric monoclonal antibody to tumor necrosis factor alpha (infliximab) versus placebo in active spondylarthropathy. Arthritis Rheum 2002;46:755-65.

8 Antoni C, Dechant C, Hanns-Martin Lorenz PD, Wendler J, Ogilvie $A$, Lueftl $M$, et al. Open-label study of infliximab treatment for psoriatic arthritis: clinical and magnetic resonance imaging measurement of reduction of inflammation. Arthritis Rheum 2002;47:506-12.

9 Feldmann M, Elliott MJ, Woody JN, Maini RN. Anti-tumour necrosis factor-alpha therapy of rheumatoid arthritis. Adv Immunol 1997;64:283-350.

\title{
Asthenoazoospermia in patients receiving anti-tumour necrosis factor $\alpha$ agents
}

\author{
G La Montagna, D Malesci, R Buono, G Valentini
}

Ann Rheum Dis 2005;64:1667. doi: 10.1136/ard.2005.038620

$\mathrm{T}$ umour necrosis factor $\alpha(\mathrm{TNF} \alpha)$ is known to affect gonadal cell viability and function by several pathways: inhibiting germ cell apoptosis'; promoting Sertoli cell androgen receptor expression and activity $^{2}$; and inhibiting Leydig testicular cell steroidogenesis at the transcriptional level. ${ }^{3}$ Recently, infliximab (that is, chimeric monoclonal anti-TNF $\alpha$ antibody) has been shown to block the survival promoting effect of $\mathrm{TNF} \alpha$ on seminiferous epithelium in vitro. ${ }^{4}$ These data prompted us to search for any alteration in gonadal function or spermatogenesis, or both, in patients undergoing anti-TNF $\alpha$ treatment.

At present, we have investigated three male patients (median age 40 years, range 35-51), all with ankylosing spondylitis (median disease duration 14 years, range 12-22), according to modified New York criteria, ${ }^{5}$ and treated with infliximab only $(5 \mathrm{mg} / \mathrm{kg} / 6$ weeks, after the induction period for 8,13 , and 24 months, respectively).

We detected no alterations in serum follicle stimulating hormone, luteinising hormone, prolactin, and testosterone levels. Nevertheless, we found asthenoazoospermia in two of the patients, who were both previously fathers of sons. We are unable to confirm that asthenoazoospermia depends only on the drug. Nevertheless, the above mentioned evidence for the effect of TNF $\alpha$ on gonadal function leads us to think that this is the case.

Further studies are needed to confirm or refute the influence of anti-TNF $\alpha$ antibody on spermatogenesis. It would be useful to know of such an effect when planning anti-TNF $\alpha$ treatment in male patients.

\section{Authors' affiliations}

G L Montagna, D Malesci, R Buono, G Valentini, Rheumatology Unit of Second University of Naples, via Pansini 5, 80131 Napoli, Italy

Correspondence to: $\operatorname{Dr} G$ La Montagna, Unità Operativa di Reumatologia, Seconda Università di Napoli, Via Pansini 5, 80131 Napoli, Italy; giovanni.lamontagna@unina2.it

Accepted 22 April 2005

\section{REFERENCES}

1 Pentikainen V, Erkkila K, Suomalainen L, Otala M, Pentikainen MO, Parvinen $M$, et al. TNF alpha down-regulates the FAS ligand and inhibits germ cell apoptosis in the human testis. J Clin Endocrinol Metab 2001;86:4480-8.

2 Delfino FJ, Boustead JN, Fix C, Walker WH. NF-kappa B and TNF-alpha stimulate androgen receptor expression in Sertoli cells. Mol Cell Endocrinol 2003;28:1-12.

3 Hong CY, Park JH, Ahn RS, Im SY, Choi HS, Soh J, et al. Molecular mechanism of suppression of testicular steroidogenesis by proinflammatory cytokine tumor necrosis factor alpha. Mol Cell Biol 2004;24:2593-604.

4 Suominen JS, Wang Y, Kaipia A, Toppari J. Tumor necrosis factor-alpha (TNF-alpha) promotes cell survival during spermatogenesis, and this effect can be blocked by infliximab, a TNF-alpha antagonist. Eur J Endocrinol 2004;151:629-40.

5 van der Linden SM, Valkenburg HA, Cats A. Evaluation of the diagnostic criteria for ankylosing spondylitis: A proposal a modification of the New York criteria. Arthritis Rheum 1984;27:361-8. 